\title{
Motivação, comprometimento e sofrimento no trabalho do setor público: Um estudo de caso em uma universidade pública de Sergipe
}

Motivation, commitment and suffering at work from public sector: A case study at a public university of Sergipe

\section{Resumo}

Este estudo objetivou analisar as condições de trabalho dos servidores de uma universidade pública de Sergipe, considerando aspectos motivacionais, de comprometimento e de sofrimento. Para tanto foi feita uma pesquisa quantitativa com uso de questionários com os chefes de departamentos e núcleos e com os técnicos administrativos, que responderam questões relacionadas ao ambiente de trabalho e relacionamento interpessoal. Os resultados revelam que as condições de trabalho desses servidores têm deficiências oriundas do formato de gestão pública, desde o que diz respeito ao ambiente de trabalho até questões de gestão do plano de carreira, aproveitamento de pessoal qualificado e condições psicológicas.
\end{abstract}

Layse de Jesus Cruz ${ }^{\mathrm{I}}$ Napoleão dos Santos Queiroz ${ }^{2}$ Glessia Silva de Lima ${ }^{3}$

Palavras-chave: Gestão de Pessoas; Motivação; Sofrimento.

\begin{abstract}
This study aimed to analyze the working conditions government employees from a public university of Sergipe, considering motivational, committal and of suffering aspects of their activities. For this, we conducted a quantitative research using questionnaires with the heads of departments and centers and the administrative staff, who answered questions related to work environment and interpersonal relationships. The results reveal that the working conditions of these government employees have deficiencies arising from the format of public management, ranging from aspects related to the workplace to issues related to the management of career plans, use of skilled personnel and psychological conditions.
\end{abstract}

Keyword: People Management, Motivation, Suffering.

\begin{abstract}
${ }^{1}$ laydear@hotmail.com, Brasil. Graduada em Administração pela Universidade Federal de Sergipe - UFS. Campus Universitário José Alóisio de Campos, Jardim Rosa Elze, CEP: 49100-000 - São Cristovão, SE - Brasil.

2npqueiroz@yahoo.com.br, Brasil. Professor Adjunto da Universidade Federal de Sergipe - UFS. Doutor em Administração pela Universidade Federal da Bahia - UFBA. Campus universitário José Aloísio de Campos, Jardim Rosa Elze, CEP: 49100-000 - São Cristovão, SE - Brasil.

33glessia@ig.com.br, Brasil. Professora Assistente da Universidade Federal de Alagoas - UFAL. Mestre em Administração pela Universidade Federal de Sergipe - UFS. Rodovia AL 145, Km 3, nº 3849, Bairro Cidade Universitária, CEP: 57480-000 - Delmiro Gouveia, AL - Brasil
\end{abstract}




\section{Introdução}

Nos dias atuais as organizações têm passado por transformações muito importantes e dentre elas estão a entrada em mercados internacionais. Diante desse contexto fez-se necessário uma inovação na gestão de recursos humanos, visto que se exige muito mais dos funcionários e espera-se deles mais do que conhecimento técnico, sendo a capacidade intelectual mais cobiçada pelas organizações. No entanto, para que as pessoas possam desenvolver e manter tais habilidades elas precisam ser estimuladas, para estarem comprometidas com o negócio (FLAUZINO; BORGES-ANDRADE, 2008).

O que se pode perceber é que as organizações valorizam cada vez mais o comprometimento das pessoas. Os funcionários comprometidos são os que vêm sendo convocados para fazer parte das soluções e é exatamente neles que as empresas mais tendem a investir. A motivação, por sua vez, como coloca Gil (2OIO), é a chave do comprometimento e pode ser entendida como o principal combustível para a produtividade da organização. Por isso, identificar fatores capazes de promover a motivação dos empregados e dominar as técnicas adequadas para trabalhar com ela vem se tornando a tarefa mais importante para os gerentes.

Como não é possível uma pessoa motivar outra, a alternativa é criar um ambiente de trabalho que estimule a ação, nesse sentido, a tarefa da administração não é motivar seus funcionários, mas, sobretudo, induzir comportamentos positivos por parte deles (ARCHER, I997). Segundo Bergamini (1997), o comportamento positivo pode ser induzido pelo uso de fatores de satisfação relacionados à necessidade, que serve como centro de organização do comportamento do empregado. Para o autor, a noção de necessidade permeia a maior parte dos conceitos de motivação, de modo que está presente em um bom número de teorias, sendo as mais comuns: reconhecimento, responsabilidades, fisiológicas, realização, socialização, materiais e poder.

Em decorrência do processo intrínseco da motivação, outra característica importante é que ela é individualizada, assim, existem pessoas que se sentem altamente motivadas para realizar determinadas tarefas, e outras acham estas mesmas tarefas desinteressantes, o que ocorre porque as pessoas têm valores diferentes, formação profissional diferente, enfim, uma história de vida que condiciona suas motivações (VERGARA, 200o). Isto implica que cada pessoa tem diferentes necessidades (fatores 
de motivação), bem como diferentes meios de atender essa necessidade (fatores de motivação), de modo que a estratégia de se trabalhar com pessoas motivadas exige mais dedicação das hierarquias, as quais devem conhecer as necessidades de cada um dos seus subordinados (BERGAMINI, I997), cabendo estas chefias o papel de estimular, incentivar e provocar a motivação (VERGARA, 2000).

Há diversas teorias sobre motivação, mas uma não anula a outra, pelo contrário, elas se complementam (BERGAMINI, I997). Com referência à motivação para o trabalho, essa também é a posição de Caudron (1997), que após uma pesquisa realizada com autores, teóricos, consultores e treinadores, concluiu que não existe uma abordagem tipo panacéia para obter a motivação, ao contrário, trata-se de um processo no qual os gerentes bem sucedidos empregam uma combinação de várias abordagens.

No que diz respeito ao setor público, estudos que envolvam motivação, satisfação e comprometimento vêm ganhando espaço, uma vez que nos últimos anos o setor público tem focado em práticas gerenciais advindas de práticas observadas no setor privado, de modo que tal mudança acaba criando a necessidade de regulações que permitam o melhor alcance dos resultados (LADEIRA; SONZA; BERTE, 2OI2). Nesse sentido, surge o que se chama de "Nova Gestão Pública", caracterizada pela inserção de práticas gerenciais do setor privado no intuito de melhorar a performance das organizações públicas, e com elas, surge a necessidade de trabalhar aspectos motivacionais que possam agir diretamente sobre o desempenho (KAISER, 2OI4).

Dentre os estudos voltados a motivação, satisfação e comprometimento no setor público, podemos destacar o de Flauzino e Borges-Andrade (2008), que investigam a relação entre o comprometimento dos servidores públicos e o alcance das missões organizacionais; o de Malik et al. (2OIO), que analisam o impacto da satisfação no trabalho sob o comprometimento nas universidades públicas do Paquistão; o de Markovits et al. (20IO), que realiza uma comparação entre satisfação e o comprometimento nos setores públicos e privados; o de Ladeira, Sonza e Berte (2OI2), que buscou identificar os aspectos que afetam a satisfação no serviço público; o de Borges (2OI3), que realiza uma comparação entre a satisfação no setor público e no setor privado; e o de Kaiser (20I4), voltado à satisfação e à motivação no trabalho do setor público da Alemanha. 
Diante do exposto, a escolha desse tema se deu pelo fato de essa ser uma temática para a qual se deve dar especial atenção, visto que motivação é uma variável que contribui para o sucesso das organizações e atualmente toda ferramenta de gestão que promova esse sucesso é de vital importância e é vista como diferencial competitivo. Ademais, a administração de recursos humanos está em uma fase muito importante, no que diz respeito a valorizar e estimular os funcionários a fim de que executem suas tarefas da melhor forma possível, mas basta atentar um pouco para o cenário organizacional para perceber que isso ainda é uma característica mais presente nas grandes empresas do setor privado.

Além disso, o estudo do fenômeno motivacional não tem como único objetivo obter um melhor desempenho dos funcionários. Numa visão humanística, uma compreensão profunda da dinâmica dos indivíduos permite aos líderes atuarem de forma consciente, buscando uma relação com os mais legítimos interesses de cada membro do corpo funcional e as demandas da organização e da sociedade (CAVALCANTI et al., 20O7).

Diante desse cenário o presente estudo tem por objetivo demonstrar o que motiva/desmotiva os funcionários no setor público, tendo como unidade de análise uma universidade pública, situada no Estado de Sergipe, buscando, por meio da aplicação de questionários, conhecer as expectativas dos servidores dessa instituição e os fatores que influenciam no processo de motivação, comprometimento e sofrimento dos mesmos, no exercício de suas atividades.

A origem da Administração de Recursos Humanos: gestão com pessoas e subjetividade

A Administração de Recursos Humanos (ARH), emergente da década de $7 \mathrm{O}$ (SCHULER, I996; IGALENS, I999) e surgiu como um campo teórico e de psicologia industrial, fundamentada nas teorias organizacionais. A ARH baseou-se nos modelos teóricos como um campo teórico e de prática, fundamentada nas tradições da psicologia industrial e das teorias organizacionais, sustentando-se nos modelos teóricos do behaviorismo organizacional anglo-saxão e na psicologia comportamentalista americanas, a fim de buscar administrar o capital humano nas empresas, potencializar os benefícios 
econômicos que resultam do entrelaçamento dos objetivos empresariais com o potencial dos empregados (BOURNOIS; BRABET, I993).

Por vezes o corpo de conhecimento da ARH teve a sua nomenclatura modificada, e esse reajuste reflete o ajustamento de certa revolução, bem como a consolidação de um processo de legitimação (BOURNOIS; BRABET, I993).

A ARH começou a ser percebida na segunda metade do século XIX, primeiro nos bancos e depois nas indústrias. Entre as décadas de 6o e 7o a ARH foi sobremaneira enriquecida com: o desenvolvimento de técnicas; a descrição e análises de cargos; o enriquecimento das tarefas; e a criação da gestão participativa por objetivos.

No entanto, somente ao final de I970 a ARH passa a considerar as pessoas como recursos à disposição da empresa, e não mais como custo, somente. Entre as transformações sofridas pela ARH nas últimas décadas, há três que devem especialmente ser destacadas: a abordagem funcionalista; a abordagem estratégica; e a abordagem política.

A Abordagem Funcionalista é um campo composto por técnicas, procedimentos e ferramentas bem definidos e distribuídos dentro da organização (SCHULER; HUBER, I993). Já a abordagem estratégica da ARH, que se inicia ao fim da década de I97o e início da de 1980 , caracteriza a influência da estratégica e forças do ambiente, e da competição internacional e nacional, de forma a se alinhar aos objetivos estratégicos da empresa (BUTLER; FERRIS; NEPIER, I99I; BOXALL, I993; MABEY; SALAMON; STOREY, I998) diante das imposições do mercado, com a finalidade de favorecer a flexibilidade e a adaptabilidade das pessoas às mudanças organizacionais e ambientais. E a abordagem política abrange tanto os indivíduos e a organização quanto as dimensões políticas da sociedade, de maneira que considera que a política pode influenciar os processos de seleção, os de avaliação de desempenho e o sucesso da carreira profissional.

Diante de todas essas características e modificações da ARH, é preciso considerar que existem críticas quanto à sua forma de atuação nas organizações. Questiona-se o fato de as pessoas serem vistas como custo e tratadas como recursos (TOWNLEY, I994; LEGGE, I995; STOREY, I995; STEYAERT; JANSSENS, I999). Esses criticam a forma de gestão desprovida de conteúdo ético, filosófico e auto-reflexivo. 
A fim de contornar essas peculiaridades da ARH, os gestores devem, antes de tudo, perceber de forma diferenciada a relação das pessoas com o mundo organizacional e do trabalho (PIMENTA, I999) e admitir que a decisão e a operacionalização de estratégias dependem das pessoas.

Um estudo realizado por Laner e Benjamim (2008) mostrou que algumas mudanças relacionadas à forma de gestão dos recursos humanos ocorreram ao fim do século XX, as funções tornaram-se mais diversificadas, menos mecânicas, surgiram novas tecnologias. Considerando as palavras de Quinn (I992), pode-se afirmar que o poder intelectual dos colaboradores passou a compor o poder econômico das empresas e não mais os fatores de produção (terra, fábrica, equipamentos). Esse autor afirma que as organizações tornaram-se repositórias e coordenadoras de inteligência. Diante disso, o papel do gestor de recursos humanos consiste em encontrar a pessoa certa para ocupar o lugar certo.

Depois de todas essas mudanças, no mesmo século a escola das relações humanas chamou a atenção desse novo modelo de gestão para a necessidade de melhores condições de trabalho. A proposta foi um redesenho e enriquecimento do trabalho a fim de que os trabalhadores se sintam motivados, bem como um estilo de liderança mais democrático.

A Figura or demonstra a relação das pessoas com o trabalho, onde o comprometimento se apresenta como um meio termo entre a motivação e o sofrimento.

Figura or: Modelo adaptado das teorias clássicas - Norte americanas e Européias

Fonte: Pesquisa teórica (2OII)
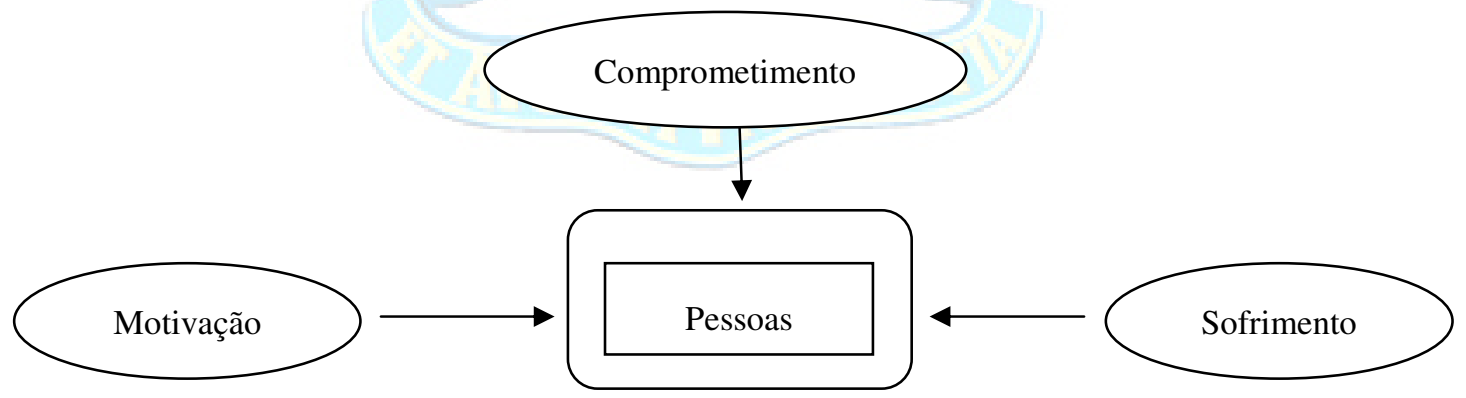

Motivação no trabalho 
Sônia Guedes Gondim e Narbal Silva, em sua participação na composição do livro Psicologia, Organização e Trabalho (ZANELLI; BORGES; BASTOS, 2004), fazem o seguinte questionamento: Como entender que uma pessoa se sinta motivada a solucionar uma complicada questão matemática enquanto que outra prefere pedir a alguém para ajudá-la a responder rapidamente? Como entender que alguém passe uma noite lendo um livro aparentemente desmotivador? O que nos move? Esse é o questionamento feito por séculos por psicólogos, gestores e tantos outros que tentam mensurar a motivação humana.

Muitas teorias são apresentadas, respostas diversas são dadas e cada dia mais esse é um tema que envolve muito mais que remuneração e carga horária de trabalho. Motivação envolve satisfação, desejo, energia, recompensas intrínsecas e extrínsecas, comprometimento, envolvimento, ajustamento no trabalho, desenho de cargo, crenças, valores, metas, expectativas e, mais recentemente, criatividade, cultura, afeto e trabalho em equipe, é o que explica Ambrose e Kulik (1999)

Motivação pode, ainda, ser entendida como uma ação dirigida a objetivos, sendo auto-regulada, biológica ou cognitivamente persistente no tempo e ativada por um conjunto de necessidades, emoções, valores, metas e expectativas. (SALANOVA; HONTAGAS; PEIRÓ, I996).

Na Figura o2 são apresentados os principais aspectos envolvidos no conceito de motivação e que repercutem na construção de teorias sobre esse processo psicológico. 
Figura 02: Listagem dos principais fatores implicados na motivação, ressaltando as perguntas demandadas e as respostas presentes nas teorias da motivação
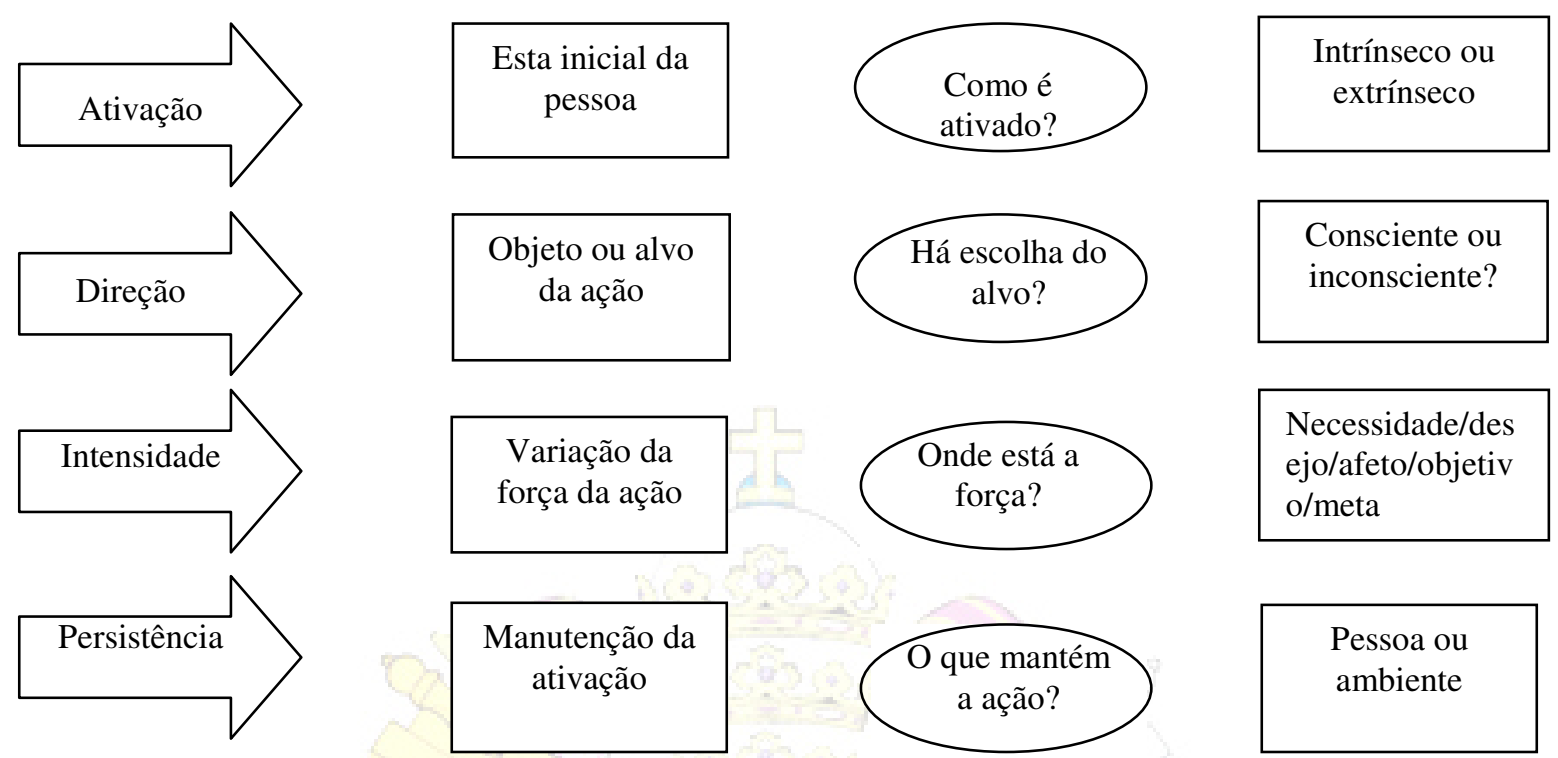

Consciente ou inconsciente?

Fonte: Zanelli, Andrade e Bastos (2004)

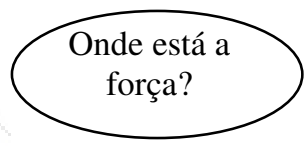

Necessidade/des ejo/afeto/objetiv o/meta

Pessoa ou

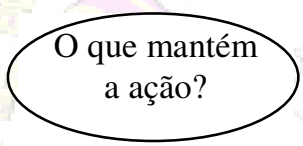

ambiente

\section{Teorias Clássicas de Motivação: Viés Norte-Americano}

De acordo com Gil (20IO), as teorias clássicas existentes sobre motivação originam-se do princípio de que, com oportunidades e estímulos adequados, as pessoas trabalham mais contentes. O fato de a motivação ser tão complexa fez com que aparecessem diferentes teorias para a aplicação desse fenômeno, tais como a teoria das necessidades - Maslow, Mcclelland, Alderfer; a teoria dos dois fatores - Herzberg, Mausner e Snyderman; a teoria das expectativas ou instrumentalidade - Vroom; a teoria do reforço - Skinner e Collenan; a teoria dos objetivos - Locke e Bryan; a teoria da equidade - Homans e Adams, para mencionar apenas as mais influentes.

Cinco das principais teorias de motivação são tratadas a seguir: teoria da hierarquia das necessidades de Maslow, teoria das necessidades socialmente adquiridas de McClelland, teoria da motivação-higiene de Herzberg, teoria da equidade de Homans e Adams e teoria das expectativas de Vromm.

\section{Teoria da hierarquia das necessidades de Maslow}

Uma das teorias mais conhecidas no campo da motivação humana é a da hierarquia de necessidades de Maslow. Para esse autor, o que move o ser humano é a 
busca da satisfação das necessidades. Essas necessidades podem ser de diversas naturezas e estão dispostas segundo uma hierarquia de predominância, de modo que na base da escada, estão as necessidades fisiológicas, como respiração, fome, sede, sono. Logo acima, a necessidade de segurança, que envolve o senso de estabilidade e proteção contra danos físicos e emocionais. Acima, as necessidades sociais, incluindo interação social, afeição, companheirismo e amizade. A seguir, a necessidade de estima, como auto-respeito, amor-próprio, autonomia, status, reconhecimento, consideração, envolvendo crescimento pessoal, auto-satisfação e realização do próprio potencial.

Para Maslow, segundo Gil (2OIO), enquanto não estiverem satisfeitas, as necessidades situadas mais na base da hierarquia permanecem predominantes na determinação do comportamento, porém, quando satisfeitas, passam a não mais motivar. O atendimento da necessidade logo acima passaria, então, a direcionar as ações do indivíduo.

Adicionalmente, Maslow reconhece que a hierarquia das necessidades não é rígida, podendo existir exceções, como pessoas em que o impulso à criatividade é mais importante que qualquer outro contradeterminante (SAMPAIO, 2004). Esse é o caos de muitos artistas que sacrificam o seu bem-estar financeiro em prol de sua realização pessoal, porém, mesmo não sendo rígida, essa hierarquia fornece compreensões importantes para pautar a ação gerencial, por exemplo, tentar mobilizar funcionários que estão com fome, oferecendo integrações sociais, pode não surtir efeito algum, um lanche pode ser mais efetivo (VERGARA, 2003).

Morgan (1996) assinala que tal teoria exerceu um grande impacto na área de gestão, tendo em vista que muitas organizações buscavam provocar a motivação dos funcionários apenas pelo dinheiro ou segurança no emprego. Abriu-se o espaço para novas práticas de gestão, de forma a criar condições de crescimento pessoal que, ao mesmo tempo, contribuíssem para que fossem atingidos os objetivos organizacionais.

\section{Teoria das necessidades socialmente adquiridas de Mcclelland}

McClelland (I997) pesquisou padrões motivacionais em diferentes indivíduos, identificando três tipos de necessidade: realização, afiliação e poder. Assim, para o autor, realização refere-se à necessidade de superar desafios e atingir metas; afiliação, às 
necessidades sociais, de relacionamento e pertencimento; e poder, à necessidade de influenciar pessoas e situações, uma vez que, em momentos diferentes, somos influenciados por necessidades diferentes, de acordo com a situação. Porém, cada indivíduo possui uma tendência dominante para uma determinada necessidade, desenvolvida ao longo da vida, a partir da sua história e experiências, englobando a família, escola e cultura na qual cresceu, e, tais necessidades, mesmo no adulto, não são fixas e imutáveis, podendo ser aprendidas (BOWDITCH; BUONO, 1992)

A partir da classificação dos indivíduos por necessidades dominantes, várias pesquisas foram realizadas. Davis e Newstrom (I992) assinalaram que funcionários orientados para a realização dão valor a trabalhar com pessoas tecnicamente capazes e a receber uma avaliação detalhada de seu gerente sobre seu comportamento no trabalho, bem como são estimuladas por discursos em que a tônica seja a superação de desafios e a busca de excelência. Assim, segundo o autor, pessoas com motivação para afiliação trabalham melhor quando elogiadas por atitudes de cooperação, valorizando trabalhar entre amigos, enquanto indivíduos com orientação para o poder buscam criar um impacto em suas organizações, assumindo riscos ao fazê-lo.

Outra consideração importante, de acordo com Robbins (2002), diz respeito à identificação dos perfis de necessidade associados a um bom desempenho em diferentes setores de trabalho. Conforme o autor, a partir dessa identificação, os indivíduos poderiam passar por programas de treinamento, com o objetivo de trabalhar as suas necessidades, ampliando umas e reduzindo outras, o que consistiria em valioso recurso para o desenvolvimento de competências, por exemplo, um indivíduo com grande necessidade de realização não será, necessariamente, um bom gerente, pois as pessoas com tal necessidade estão interessadas na eficácia com que trabalham e não em influenciar os outros a ter um bom desempenho.

Ainda de acordo com Robbins (2002), existem indicações de que uma necessidade moderada para alta de poder combinada com uma necessidade baixa de afiliação, por sua vez, contribui para o desempenho gerencial, pois a alta necessidade de poder cria desejo de ter influência ou impacto sobre os outros e a necessidade baixa de afiliação permite que o gerente tome decisões difíceis sem o receio de que não gostem dele. Um aspecto relevante, de repercussões na esfera ética, é a afirmação de McClelland 
e Burnham (I997, p. ı3I): “Acima de tudo, a motivação de poder do bom gerente não é orientada para seu engrandecimento pessoal, mas para a instituição a qual ele serve”.

\section{Teoria da motivação: Higiene de Herzberg}

A partir dos anos I96o Herzberg (I997 apud DUBRIN, 200I) realizou pesquisas em que perguntava a funcionários que eventos ocorridos no trabalho os levaram à extrema satisfação ou extrema insatisfação. A partir dos resultados, identificou alguns fatores envolvidos na produção da satisfação no trabalho. Os primeiros, que chamou de motivadores, são fatores de crescimento e relacionam-se ao trabalho em si, como execução da atividade, reconhecimento recebido, conteúdo do trabalho, responsabilidade e desenvolvimento, e os últimos, chamados de fatores de higiene, são externos à atividade, como política e administração da empresa, supervisão, relacionamentos interpessoais, condições de trabalho, salário, status e segurança.

A principal implicação dessa teoria é que uma concentração nos fatores higiênicos apenas impede a insatisfação no trabalho. Para que os empregados fiquem satisfeitos e obtenham um maior desempenho, torna-se necessário incorporar fatores motivadores ao trabalho. Para motivar, além disso, segundo Herzberg (I997 apud DUBRIN, 2OOI), é necessário o enriquecimento dos cargos, de forma a proporcionar mais autonomia, senso de realização, responsabilidade e desenvolvimento aos funcionários.

A pesquisa de Herzberg tem certa simplicidade e não considerou que as pessoas tendem a atribuir seus sentimentos de satisfação a si mesmo e a insatisfação, aos outros (VERGARA, 2003). Adicionalmente, a princípio, estar satisfeito não garante motivação, pois “necessidades satisfeitas não mais motivam”. Porém, as conclusões a que a pesquisa chegou fazem sentido e se articulam bem coma a teoria de Maslow. As necessidades na base da pirâmide, se em falta, geram desconforto; porém, se atendidas, não mais motivam. As necessidades no topo da pirâmide, por sua vez, se satisfeitas, continuam motivando.

\section{Teoria da Equidade de Homans e Adams}

Segundo essa teoria, as pessoas não estão apenas interessadas nas recompensas absolutas que recebem pelo seu trabalho, mas são bastante sensíveis às diferenças 
relativas entre seus pares, isto é, estão sempre se comparando, buscando garantir que não estão sendo tratadas de forma injusta, recebendo menos que os outros pelo mesmo esforço; comparam o que recebem da organização com aquilo que os outros funcionários, de características parecidas, recebem, assim, mesmo um indivíduo que ganhe bastante pode se desmotivar por não se sentir tratado de forma equânime (ROBBINS, 2002).

De acordo com Bowditch e Buono (1992), as pessoas, então, comparam a relação entre suas contribuições ao trabalho (como o esforço e a habilidade) e as recompensas recebidas (como o pagamento e a promoção) com as relações entre contribuições e recompensas de pessoas semelhantes. De modo que ao perceberem um desequilíbrio, buscam restaurá-lo, seja diminuindo o ritmo de trabalho ou tentando obter recompensas maiores por outros meios, dedicando-se a outras atividades ou até deixando a organização.

\section{Teoria da Expectativa de Victor Vromm}

Essa teoria confere uma das explicações mais aceitas sobre motivação, apesar de ter alguns críticos. Victor Vromm, desenvolveu um modelo contingencial de motivação, baseando-se na observação que o processo motivacional não depende apenas dos objetivos individuais, mas também do contexto e trabalho em que o indivíduo está inserido (QUEIROZ, I996). Para Vromm (I964 apud FERREIRA; FUERTH; ESTEVES, 2006), a motivação é um processo que governa as escolhas entre diferentes possibilidades de comportamento do indivíduo, que avalia as consequências de cada alternativa de ação e satisfação, que deve ser encarada como resultante de relações entre as expectativas que a pessoa desenvolve e os resultados esperados.

Em termos práticos, esta teoria sugere que um funcionário se sente motivado a despender um alto grau de esforço quando isto resultar em uma boa avaliação de desempenho; que boa avaliação de desempenho vai resultar em recompensas organizacionais, tais como bonificação, aumento de salário ou promoção; e estas vão atender suas metas pessoais (ROBBINS, 2002). De acordo com Vromm (I964 apud ROBBINS, 2002), a teoria da expectativa ajuda a explicar por que tantos trabalhadores não se sentem motivados em seu trabalho e fazem o mínimo para continuarem empregados. 
Em contrapartida a essa teoria, os críticos afirmam que para que uma pessoa seja capaz de estabelecer uma relação clara entre seu desempenho e os resultados obtidos é necessário que tenha acesso a diversas informações, a fim de analisá-las e poder tirar suas conclusões, e esse acesso, normalmente, não é permitido.

Teorias Européias sobre Motivação e Gestão de Pessoas: Foco na Crítica Organizacional

Até aqui foram apresentadas teorias e questões relacionadas à motivação no trabalho. No entanto, existe também o viés europeu, que trata dessa questão da motivação de forma diferente dos autores norte-americanos citados anteriormente.

Dejours (1992), em "a loucura do trabalho", estudo de psicologia do trabalho de Christophe Dejours, apresenta o trabalho como um fator de sofrimento e insatisfação a ser contornado, percebido muito claramente no serviço operário, com a revolução. $\mathrm{Na}$ perspectiva do autor, a indignação com a tarefa surge do contato forçado com uma tarefa desinteressante, sem significância, gerando, assim, um sentimento de inutilidade por parte do trabalho, de modo que, começando pelo serviço operário e estendendo-se até os mais renomados escritórios, não é difícil encontrar nos melhores setores pessoas que se sentem inúteis e insatisfeitas, seja por causa do serviço em si, do ambiente de trabalho ou das recompensas, comprometendo assim o serviço prestado, bem como seus resultados e todo o processo de motivação, vagamente abordado. Nesse sentido, Dejours (I992) argumenta que mais do que isso, sua tarefa não tem significado humano, ela não significa nada para a família, para os amigos, nem para o grupo social e nem para o quadro de um ideal social, altruísta, humanista e político.

Discorrendo sobre o tema motivação, Motta e Freitas (2000), ao tratarem da vida psíquica e organização, tem a dizer que a cada dia os indivíduos tornam-se individualistas e autônomos, assim, embora esse venha a ser o sonho coletivo, dentro das organizações, quanto mais se estimula a originalidade e a autonomia, mais se prende o indivíduo nas "grades” (Rousseau) sutis e tão ilustres que chegam a ser cobiçadas.

Diante da agitação do capitalismo e do grande movimento econômico mundial, as organizações estão, cada vez mais, preocupadas em ser o "autor principal” da sociedade, no entanto, para isso é necessário que os agentes humanos que os move estejam motivados. Percebe-se aqui que a preocupação não é com o bem estar do 
trabalhador assalariado, no sentido de preocupação humana, mas sim, todo empenho feito com relação a estimular esses agentes, têm em vista o bem da organização, seu crescimento, o alcance da posição de "autor principal da sociedade" (MOTTA; FREITAS, 1992).

Nesse modelo de organização atual e da racionalidade ilimitada, o poder pertence aos "espertos" que, supõe-se possuem os elementos do conhecimento, o que lhes dá a possibilidade não só de resolver de maneira ótima os problemas colocados, mas também de antecipar seu surgimento. Esse tipo de estrutura organizacional original do capitalismo, busca nos indivíduos características como: a integração de cada um à organização e a idealização dela mesma; um espírito individualista e ao mesmo tempo um forte espírito de equipe.

Com tudo isso, percebe-se que a empresa estratégica quer a participação de todos. De fato, não é mais do que uma elite que desfruta da adesão maciça à dinâmica organizacional. Para a maioria, o trabalho torna-se menos interessante, o risco de desemprego cresce, a precariedade do trabalho aumenta, as promoções são bloqueadas. Fala-se tanto mais de participação quanto na realidade a possibilidade e o desejo de participação diminuem. A "histeria” e a "teatralidade” encontram seus limites. O mundo das aparências começa a aparecer como um mundo de mistificação, na qual a busca por perfeição, idealização e entrega do funcionário, confrontada com a incerteza da estabilidade nas empresas, gera no colaborador um instinto que faz com que ele planeje estrategicamente seu próprio futuro, sem se preocupar com lealdade à empresa.

\section{Gestão Pública}

Para falar sobre gestão de pessoas no setor público é necessário primeiramente entender seu conceito e sua relação com recursos humanos. Gestão, isoladamente, é um termo que pode ser entendido como equivalente à administração, que envolve o processo contínuo de planejar, organizar, dirigir e controlar.

Segundo esse pensamento, gestão de pessoas no setor público pode ser entendida por: esforço orientado para o suprimento, a manutenção e o desenvolvimento de pessoas nas organizações públicas, em conformidade com os ditames constitucionais 
e legais, observadas as necessidades e condições do ambiente em que se inserem (BERGUE, 2OIO).

Essa gestão orientada a pessoas envolve ações de planejamento que consideram as necessidades das organizações e das pessoas; a busca e alocação dos recursos que suprirão tais necessidades; e o controle dessas aplicações, a fim de que resulte num processo eficiente.

Assim como qualquer organização, a administração pública recebe insumos, processa-os e gera produtos. Seus produtos são bens e serviços públicos postos à disposição coletivamente, de modo que entidades públicas se utilizam de elementos, recursos materiais e humanos, para produzir bens e serviços, é o que explica Bergue (2OIO).

Algumas particularidades do setor público precisam ser consideradas, como quem são seus financiadores e seus agentes. Enquanto nas empresas privadas o cliente que consome o bem ou serviço é o mesmo que paga por ele, no setor público o financiador e o consumidor podem ser segmentos sociais bem distintos. Além dos financiadores dos serviços/produtos públicos, temos seus agentes, que são seus recursos humanos, esses são todas as pessoas que prestam serviços ao Estado e as pessoas jurídicas de administração indireta (autarquias, fundações, empresas públicas e sociedades de economia mista, podendo ser classificados conforme o Quadro oI (DI PIETRO, I999):

Quadro oI: Financiadores dos serviços/produtos públicos

\begin{tabular}{|c|l|}
\hline Classificação & \multicolumn{1}{c|}{ Componentes } \\
\hline \multirow{3}{*}{ Agentes Políticos } & $\begin{array}{l}\text { a) Componentes do Governo - presidente, governador e prefeito - e seus imediatos - ministros e } \\
\text { secretários; } \\
\text { b) Membros das Corporações Legislativas - senadores, deputados, juízes e desembargadores; } \\
\end{array}$ \\
& $\begin{array}{l}\text { C) Membros do Ministério Público - promotores e procuradores de justiça; d) Membros do Tribunal de } \\
\text { Contas - ministros, conselheiros e auditores substitutos. }\end{array}$ \\
\hline Servidores & $\begin{array}{l}\text { a) Estatutários - ocupam cargos públicos e são regulados por estatuto próprio, o dos servidores públicos; } \\
\text { públicos }\end{array}$ \\
& $\begin{array}{l}\text { b) Empregados públicos - regidos pela Consolidação das Leis do trabalho (CLT), ocupantes de } \\
\text { c) Servidores Temporários - admitidos por tempo determinado, ou necessidade temporária. }\end{array}$
\end{tabular}

Fonte: Di Pietro (I999)

Diante do exposto, como entender o processo de motivação no setor público? Existem características de natureza cultural, política, econômica, legal, etc., que tornam 
esse setor diferente do privado. Quando perguntados sobre o que os levou a escolherem o setor público, os servidores logo falam de fatores como: remuneração, estabilidade e status.

Existem no setor público alguns programas de estímulo e de motivação que Bergue (2OIO) descreve em seu trabalho mais recente, e são eles: programa de reconhecimento de servidores; programa de envolvimento de servidores; programa de remuneração variável; programa de remuneração por habilidades adquiridas; programas de envolvimento social; programas de flexibilização de horário de trabalho.

Já para os servidores temporários, há os seguintes fatores, administrados pela gestão que intenta motivá-los, são eles: estímulo à participação em programas de treinamento para desenvolvimento pessoal e das atividades desenvolvidas; valorização e reconhecimento; e melhoria das condições e relações de trabalho.

Tais programas e a preocupação com a motivação dos servidores públicos e o seu desempenho refletem o estado atual da gestão pública, cada vez mais focada em resultados. Assim, estudos que envolvam motivação, satisfação e comprometimento vêm ganhando espaço, uma vez que nos últimos anos o setor público tem focado em práticas gerenciais advindas de ações observadas no setor privado, de modo que tal mudança acaba criando a necessidade de regulações que permitam o alcance de melhores resultados (LADEIRA; SONZA; BERTE, 2OI2). Nesse sentido, surge o que se chama de "Nova Gestão Pública”, caracterizada pela inserção de práticas gerenciais do setor privado no intuito de melhorar a performance das organizações públicas, e com elas, surge a necessidade de trabalhar aspectos motivacionais que possam agir diretamente sobre o desempenho (KAISER, 20I4).

Embora a inserção de programas de incentivos aos servidores públicos seja um fator de apoio ao desempenho de suas funções, estes devem ser implantados com cautela. Weibel, Rost e Osterloh (2009), ao investigarem se os resultados gerados pelo pagamento por desempenho estão condicionados a condições e de que forma estas condições podem afetar positiva ou negativamente o desempenho, defendem que existem peculiaridades que podem limitar a adoção de pagamento por desempenho no setor público. Em seus resultados, os autores descobriram que a remuneração somente afeta positivamente o desempenho se houver motivação, sendo uma condição 
determinante ao desempenho, e que muitas vezes pagar por desempenho pode afetar de forma negativa o ímpeto pessoal de alcançar um bom desempenho. Nesse sentido, o pagamento por desempenho normalmente acaba gerando um custo maior do que o seu retorno e se reflete em resultados modestos no setor público.

Além destes resultados, Weibel, Rost e Osterloh (2009) também observaram que o pagamento por desempenho aumenta o desempenho para tarefas pouco interessantes, mas diminui o desempenho para tarefas interessantes. Tal aspecto vai ao encontro das afirmações feitas por Dejours (1992), em "a loucura do trabalho", que afirma que tarefas consideradas desinteressantes tendem a desmotivar.

No que se refere ao nível de satisfação no setor público e no setor privado, Borges (2OI3), ao realizar um estudo comparativo entre a satisfação nos dois setores, observou que os servidores públicos estão menos satisfeitos do que os profissionais do setor privado no que diz respeito à compensação e crescimento profissional. Entretanto, em aspectos específicos da satisfação, como ambiente social e estabilidade no trabalho, os servidores públicos estão mais satisfeitos. Tais resultados demonstram que as práticas de elevação de desempenho a serem aplicadas no setor público têm que levar em consideração que os servidores deste setor possuem motivações diferentes.

Assim, Markovits et al. (2OIO), também ao realizarem uma comparação entre satisfação e o comprometimento nos setores públicos e privados, questionam de que forma práticas voltadas ao desempenho das atividades podem ser concebidas da mesma forma se os setores apresentam características que os diferenciam. Segundo os autores, comprometimento e satisfação no trabalho são fortemente influenciados pelo contexto organizacional, o que reforça ainda mais a necessidade de se pensar de forma diferenciada em como gerir esses dois aspectos no ambiente público, tendo em vista que aspectos intrínsecos e extrínsecos à satisfação são mais determinantes para o setor público do que para o privado.

\section{Gestão Pública nas Universidades}

A educação pública e, em especial, a de nível superior teve seu cenário competitivo e de atuação modificado significativamente com a ampliação da economia, 
decorrente da globalização e da crescente busca por profissionais. Como então se preparar para absorver toda essa demanda?-

Laner e Benjamim (2008) descrevem alguns caminhos para que as instituições educadoras se preparem para enfrentar tais mudanças, como: desenvolver métodos e sistemas de maior eficácia; e desenvolver a capacidade inovadora e de auto-aprendizagem contínua, vinculando o ensino com a prática e, em especial, com o mundo empresarial.

Mas a pergunta é: Como realizar tais projetos? A estrutura organizacional da educação superior tem estrutura administrativa para atender essa crescente onda de busca por conhecimento? As universidades contam com o investimento necessário para receber um dos frutos da globalização, que é a massificada busca, inclusive por parte dos jovens, por conhecimento? Qual o cenário atual da estrutura administrativa das universidades, inclusive com relação aos técnico-administrativos que as compõem?

Tais respostas podem ser obtidas por meio da busca de práticas que estejam em conformidade com o comprometimento esperado e com a satisfação que os servidores das universidades públicas necessitam para exercerem bem suas atividades. Malik et al. (2OIO), ao analisarem o impacto da satisfação no trabalho sob o comprometimento nas universidades públicas do Paquistão, a fim de verificar o nível de satisfação e o comprometimento dos professores para com o seu trabalho, obtiveram que a satisfação é um fator direto de comprometimento no trabalho, além de uma supervisão eficaz e remuneração adequada.

\section{A Universidade fonte de estudo}

A Universidade escolhida como objeto de análise foi fundada em I5 de maio de I968. O Ensino Superior no Estado de Sergipe foi iniciado em I92O, vindo a funcionar em I950 com a criação das Escolas de Ciências Econômicas e de Química, a Faculdade de Direito e a Faculdade Católica de Filosofia em I95I. Em I954 criava-se a Escola de Serviço Social e em r96r a Faculdade de Ciências Médicas. Com esse número de escolas superiores foi possível pleitear a criação de uma Universidade em Sergipe. Através da Lei n. I.I94 de II de julho de I963, o Governo do Estado de Sergipe, autoriza a transferência dos Estabelecimentos de Ensino Superior existentes no Estado para a Universidade aqui analisada, ora em organização pelo Governo Federal. Quatro anos depois, foi instituída a 
Universidade, em 28 de fevereiro de 1967 , pelo Decreto-Lei n. 269 e instalada em I5 de maio de 1968, com a incorporação de o6 Escolas Superiores ou Faculdades que ministravam Io cursos administrados por o5 Faculdades e o5 Institutos. Em decorrência da Reforma Universitária Brasileira foram criados o4 Centros Acadêmicos que coordenam atualmente 26 Departamentos e I03 Cursos. Seu corpo discente evoluiu de 638, no ano da sua criação, para IO.375 até 2OII.

\section{Metodologia}

A presente pesquisa apresenta um caráter quantitativo, uma vez que objetiva entender como se apresenta a motivação e o comprometimento dos servidores públicos numa universidade pública de Sergipe por meio de cálculos extraídos dos questionários aplicados. A pesquisa pode ainda ser classificada como exploratória, tendo em vista buscar proporcionar um maior entendimento sobre a motivação, o comprometimento e o sofrimento no setor público, e descritivo, por caracterizar o objeto estudado.

Para tanto, a pesquisa questiona o grau de motivação, comprometimento e sofrimento dos funcionários (técnico-administrativos), no que diz respeito à execução de suas atividades; quais as variáveis que afetam o seu desempenho; e quais as condições de trabalho desses servidores.

Para a realização desta pesquisa foi tomado o setor público do Brasil, tendo como unidade de análise uma Universidade Pública de Sergipe. Essa escolha se deu pelo fato do exercício da motivação como ferramenta de gestão e do comprometimento como item fundamental para o sucesso organizacional estarem sendo mais amplamente abordados nos últimos anos, como reflexo de uma eminente, embora lenta e gradual, preocupação com mudanças no modelo da gestão pública nacional.

A amostra compreende os técnico-administrativos e chefes de departamentos da Universidade escolhida, sendo uma amostra não-probabilística, por acessibilidade. $\mathrm{Na}$ Universidade tem-se 5 I chefes de departamentos e núcleos e I54 técnico-administrativos lotados no campus analisado. Foram distribuídos Ioo questionários, sendo 30\% destinados aos chefes dos departamentos e núcleos e 70\% aos técnico-administrativos. No total foram obtidos i7 questionários respondidos dos chefes e 34 dos técnicos, com um retorno de $33 \%$ e $22 \%$, respectivamente. 
O questionário foi dividido em três dimensões, separadas ainda em cinco blocos, de acordo com o conteúdo das mesas, a saber: (I) Dimensão Comprometimento: Blocos A e B; (2) Dimensão Motivação: Blocos C e D; e (3) Dimensão Sofrimento: Bloco E.

Bloco A: Seção destinada a questões sobre "Comprometimento do servidor público".

Bloco B: Seção destinada a questões sobre "Ambiente de Trabalho".

Bloco C: Seção destinada a questões sobre "Política de Cargos, Salários e Carreira”.

Bloco D: Seção destinada a questões sobre "Políticas de RH visando a capacitação e o desenvolvimento do servidor público”.

Bloco E: Seção destinada a questões sobre "Fatores que geram sofrimento".

Os dados foram tratados por meio do Programa Microsoft Excel 2007, onde foram lançados e verificada a taxa de respostas para cada variável, a fim de compreender a percepção dos técnicos administrativos quanto às dimensões comprometimento, motivação e sofrimento, estando as variáveis e seus indicadores descritos no Quadro o2:

Quadro 02: Dimensões, variáveis e indicadores da pesquisa

\begin{tabular}{|c|c|c|}
\hline Dimensões & Variáveis & Indicadores \\
\hline \multirow[b]{2}{*}{ Comprometimento } & $\begin{array}{l}\text { Comprometimento do } \\
\text { servidor público }\end{array}$ & $\begin{array}{l}\text { - Comprometimento } \\
\text { - Absenteísmo } \\
\text { - Alcance de metas }\end{array}$ \\
\hline & Ambiente de Trabalho & $\begin{array}{l}\text { - Amizade } \\
\text { - Ambiente de trabalho } \\
\text { - Estilo de chefia do superior imediato } \\
\text { - Estresse } \\
\text { - Acomodações físicas }\end{array}$ \\
\hline \multirow[b]{2}{*}{ Motivação } & $\begin{array}{l}\text { Política de cargos, salários e } \\
\text { carreira }\end{array}$ & $\begin{array}{l}\text { - } \text { Cargo } \\
\text { - Plano de Carreira } \\
\text { - Salário } \\
\text { - Jornada de Trabalho }\end{array}$ \\
\hline & $\begin{array}{l}\text { Planejamento de RH visando } \\
\text { à capacitação e o } \\
\text { desenvolvimento do servidor } \\
\text { público }\end{array}$ & $\begin{array}{l}\text { - Treinamento } \\
\text { - Desenvolvimento } \\
\text { - Plano de saúde } \\
\text { - Bolsa de estudos } \\
\text { - Quadro de pessoal por unidade administrativa }\end{array}$ \\
\hline Sofrimento & $\begin{array}{l}\text { Fatores que geram } \\
\text { sofrimento }\end{array}$ & $\begin{array}{l}\text { - Assédio moral } \\
\text { - Pressões psicológicas } \\
\text { - Preconceito } \\
\text { - Doença } \\
\text { - Discriminação }\end{array}$ \\
\hline
\end{tabular}

Fonte: Pesquisa Teórica (2OII)

Revista Administração em Diálogo ISSN 2178-0080

Programa de Estudos Pós-Graduados em Administração Pontifícia Universidade Católica de São Paulo 


\title{
Análise e Discussão dos Resultados
}

\author{
Perfil dos Entrevistados
}

Tabela or: Perfil dos entrevistados

\begin{tabular}{|l|l|l|}
\hline & Chefes & Técnico-administrativos \\
\hline Sexo & $53 \%$ masculino & $60 \%$ masculino \\
& $47 \%$ feminino & $40 \%$ feminino \\
\hline \multirow{5}{*}{ Idade } & $6 \%$ entre 20 e 30 anos & $37 \%$ entre 20 e 30 anos \\
& $12 \%$ entre 31 e 40 anos & $20 \%$ entre 31 e 40 anos \\
& $47 \%$ entre 41 e 50 anos & $9 \%$ entre 41 e 50 anos \\
& $12 \%$ entre 51 e 60 anos & $29 \%$ entre 51 e 60 anos \\
& $23 \%$ mais de 60 anos & $5 \%$ mais de 60 anos \\
\hline \multirow{5}{*}{ Tempo de serviço } & $18 \%$ até 3 anos & $30 \%$ até 3 anos \\
& $12 \%$ entre 4 e 6 anos & $11 \%$ entre 4 e 6 anos \\
& $6 \%$ entre 7 e 10 anos & $13 \%$ entre 7 e 10 anos \\
& $41 \%$ entre 11 e 20 anos & $19 \%$ entre 11 e 20 anos \\
& $23 \%$ acima de 20 anos & $27 \%$ acima de 20 anos \\
\hline
\end{tabular}

Fonte: Pesquisa de Campo (2OII)

Ao se analisar o perfil dos entrevistados, percebe-se nos chefes de departamento e núcleos que a proporção entre homens e mulheres é quase proporcional, enquanto nos técnicos há uma predominância do sexo masculino no desempenho da função. Quanto à idade dos respondentes, nota-se que no caso dos chefes há uma maior concentração de pessoas com idade entre $4 \mathrm{I}$ e $5 \mathrm{O}$ anos, com $47 \%$, e mais de 60 anos, com $23 \%$, o que pode ser explicado em virtude do cargo; já nos técnico-administrativos a concentração reside em funcionários entre 20 e 30 anos, com 37\%, e entre $5^{\text {I }}$ e 60 anos, com $29 \%$. Por fim, em relação ao tempo de serviço, os chefes apresentam tempo entre II e 20 anos em 4I\% dos respondentes e acima de 20 anos com $23 \%$; enquanto que nos técnicos administrativos a predominância é de $30 \%$ com até 3 anos de serviço e $27 \%$ com mais de $2 \mathrm{O}$ anos.

\section{Dimensão Comprometimento}

Analisando a Dimensão Comprometimento, tendo por base todas as teorias norte-americanas e européias citadas na fundamentação teórica deste trabalho, observou-se que no trabalho do servidor público existem vários fatores que contribuem com o seu comprometimento. 
Na Universidade estudada existe um paradoxo: embora chefes e técnicos achem o trabalho uma satisfação, grande parte dos técnicos entrevistados estão contando o tempo para se aposentar ou não pretendem se aposentar. Outro questionamento fortalece ainda mais esse paradoxo: mesmo achando o trabalho uma satisfação, os técnicos administrativos não perderiam a oportunidade de trabalhar em outro lugar, inclusive estão se preparando para o surgimento de tal oportunidade. Isso é tão verdade que boa parte dos chefes percebe tal desejo. No entanto, $35 \%$ dos chefes acreditam que os técnicos não se arriscariam a sair da Universidade, tendo em vista que, conforme chefes e técnicos, diante do mercado de trabalho atual, é melhor trabalhar no setor público. Diante do exposto, entende-se que há certo conformismo com o trabalho, por conta de o mercado de trabalho não oferecer muitas outras opções que tragam estabilidade, por exemplo.

Esse resultado corrobora com o estudo de Borges (20I3), que observou que os servidores públicos estão menos satisfeitos do que os profissionais do setor privado no que diz respeito à compensação e crescimento profissional. Entretanto, em aspectos específicos da satisfação, como ambiente social e estabilidade no trabalho, os servidores públicos estão mais satisfeitos. Embora o setor público apresente estabilidade, normalmente os que nele ingressam não têm a possibilidade de mudarem de cargo e galgarem posições que denotem crescimento profissional. Tal situação afeta o desempenho, causando frustração quanto a novas possibilidades pessoais e de carreira.

Nesse sentido, pode-se observar que o tão sonhado comprometimento dos servidores para com a instituição tem suas falhas, falhas essas que puderam ser bem explicitadas quando se fala de oportunidades externas e aposentadoria. Entende-se que, no caso dos técnicos, conforme autores europeus como Dejours (I992), o trabalho não é um fator que gere motivação, mas sim uma necessidade a qual se deve estar pronta para executá-la. Entretanto, os chefes têm opinião diferente, acreditam que seus subordinados vêem o trabalho com felicidade, embora encarem a semana como mais uma rotina a ser cumprida.

No que diz respeito à relação entre eles, os chefes vêem sua relação com os técnicos como sendo respeitosas e afetuosas, e os técnicos, por sua vez, dizem que têm de tudo um pouco (respeito, afeto, conflito e desrespeito), mas uma boa parte dos 
mesmos considera essa relação respeitosa.

Pôde-se ver até aqui que, com altos e baixos, o trabalho do servidor público é executado com certo grau de comprometimento. No entanto há vários fatores que podem influenciar o desempenho do servidor público na execução dos seus serviços nas organizações. A teoria da equidade, defendida pelos autores Homans e Adams trata de um tema que foi questionado aos chefes e técnicos. A teoria diz que para que os colaboradores de uma instituição sintam-se motivados e comprometidos com a mesma, é preciso que sejam incentivados, por meio de gratificações e promoções. Outra importante teoria, a da Expectativa, defendida pelo autor Vromm, afirma que o processo motivacional não depende somente dos objetivos individuais, mas também dos coletivos. Assim, os colaboradores se sentem motivados quando despendem esforços dentro de uma organização, mas esperam ser recompensados por tal esforço, e isso deve se dá principalmente por meio de promoções e gratificações (ROBBINS, 2002).

Nesse sentido, os chefes e os técnicos foram questionados quanto à freqüência com que esses são agraciados pela gerência, com promoção no trabalho (ação essa que gera comprometimento e motivação no colaborador). Tanto os chefes quanto os técnicos afirmaram que isso quase nunca acontece, e que algumas das vezes que aconteceu, a promoção foi recusada por conta de a gratificação ser muito baixa. Os técnicos estão mais interessados em melhores salários que em promoções pouco gratificadas. Nisso se vê o retrato do serviço público no Brasil, há pouco incentivo ao desenvolvimento e comprometimento do servidor com a instituição, embora isso seja constantemente cobrado.

Tal resultado remete aos resultados encontrados por Weibel, Rost e Osterloh (2009), ao afirmarem que muitas vezes pagar por desempenho pode afetar de forma negativa o ímpeto pessoal de alcançar um bom desempenho. Assim, gratificações pouco representativas diante de novas atribuições podem despertar no servidor o sentimento de desvalorização da atividade que lhe é repassada.

Por fim, segundo os próprios técnicos, um dos mais importantes fatores que geram satisfação no seu trabalho é sua relação com os colegas, logo após vem as condições de trabalho e o salário. Os chefes por sua vez disseram que o que mais gera satisfação nos técnicos são as condições de trabalho, depois o salário e a jornada de 
trabalho. Aqui se tem um novo paradoxo: os técnicos, em sua maioria, disseram preferir uma jornada de trabalho de seis horas, e os chefes disseram ser a jornada de oito horas motivo de satisfação para os técnicos. Os chefes também não consideram os colegas de trabalho como um dos mais importantes fatores que geram satisfação nos servidores. Com base nessas respostas pode-se dizer que, nem sempre, os chefes conseguem perceber as reais necessidades e sentimentos dos seus subordinados, faltando aqui uma relação que não seja só respeitosa, mas também íntima, para que todas as ações e anseios estejam em harmonia.

\section{Dimensão Motivação}

Motivação é um processo que governa as escolhas entre diferentes possibilidades de comportamento do indivíduo, que avalia as conseqüências de cada alternativa de ação e satisfação, que deve ser encarada como resultante de relações entre as expectativas que a pessoa desenvolve e os resultados esperados (VROMM, I964 apud FERREIRA; FUERTH; ESTEVES, 2006)

No que se refere à motivação, o salário se mostrou um importante fator motivador. Assim, tanto chefes quanto técnicos concordam que esse deveria ser melhor. Outro fator foi a compatibilidade da escolaridade do servidor com a exigência do cargo. $35 \%$ dos técnicos questionados disseram ter nível superior e o cargo exigir somente nível médio, embora os chefes acreditem que esse percentual seja de $53 \%$. Outros $15 \%$ dos técnicos estão em cargos de nível médio, mas estão cursando faculdade e I8\% tem mestrado e/ou doutorado e ocupam cargo de nível médio dentro da universidade.

Esses fatores se apresentam como pontos críticos para a motivação dos servidores e demonstram manter certa relação. Por possuírem uma formação além do cargo é natural que os servidores julguem que os salários pagos são inferiores ao esperado. Além disso, a motivação para o desempenho das atividades também é afetada, uma vez que possuem competências, decorrentes da formação, que lhes permitiriam desempenhar funções aquém das exercidas.

Tais necessidades podem ser explicadas pela Teoria da Expectativa de Victor Vromm, que pontua que um funcionário se sente motivado a despender um alto grau de esforço quando isto resultar em uma boa avaliação de desempenho; que boa avaliação de 
desempenho vai resultar em recompensas organizacionais, tais como bonificação, aumento de salário ou promoção; e estas vão atender suas metas pessoais (ROBBINS, 2002). Sem isso, ocorre desmotivação mediante o sentimento de desvalorização do trabalho.

Esse é um dos quadros mais críticos dentre os pontos analisados, pois como falar em motivação e comprometimento com servidores que, podendo ocupar cargos de direção e até mesmo outra função dentro da universidade, continuam como técnicos administrativos? Somado a isso, apesar da universidade fornecer cursos de atualização e especialização, $38 \%$ dos técnicos não participaram de nenhum desses cursos.

Esse descompasso pode ser explicado mediante a "Teoria da motivação: Higiene de Herzberg", onde Herzberg (I997 apud DUBRIN, 200I) aponta que para que os empregados fiquem satisfeitos e obtenham um maior desempenho, torna-se necessário incorporar fatores motivadores ao trabalho. Segundo o autor, para motivar é necessário o enriquecimento dos cargos, de forma a proporcionar mais autonomia, senso de realização, responsabilidade e desenvolvimento aos funcionários.

\section{Dimensão Sofrimento}

Sofrimento é qualquer experiência aversiva (não necessariamente indesejada), geralmente associada à dor e infelicidade, embora qualquer condição possa gerar sofrimento se for subjetivamente aversiva.

Quando perguntados (técnicos e chefes) sobre ocorrências na Universidade de fatos como assédio físico e moral, pressões psicológicas e constrangimentos, agressões físicas ou morais por parte dos colegas ou do chefe, 7 \% \% dos chefes disseram ser o ambiente de trabalho bastante cordial, enquanto apenas $38 \%$ dos técnicos confirmam isso. Somado a isso, $26 \%$ dos técnicos disseram já ter sofrido pressões psicológicas e/ou constrangimentos indiretos.

Quando perguntados sobre a ocorrência de perseguição no setor de trabalho, enquanto $62 \%$ dos chefes disseram que o ambiente de trabalho é bastante respeitoso, apenas i2\% dos técnicos disseram o mesmo, e 47\% dos técnicos disseram já terem sido perseguidos por chefes de outros departamentos.

Ao serem questionados, chefes e técnicos, se já tiveram algum sentimento de mal 
estar no trabalho, 38\% dos chefes disseram que seus subordinados são muito saudáveis, de modo que isso nunca aconteceu, enquanto que $56 \%$ dos técnicos informaram que se sentem mal no trabalho. Aliado a isso, 44\% dos técnicos disseram já terem sofrido descriminação, injustiça e desprestígio no trabalho, enquanto que 41\% dos chefes acham que isso nunca acontece.

Esses resultados se mostram preocupantes por dois motivos, o primeiro ao demonstrar que os chefes não conhecem o real sentimento dos funcionários quanto ao ambiente de trabalho, e o segundo ao mostrar o ambiente de trabalho como um fator de desmotivação.

Ladeira, Sonza e Berte (20I2), na tentativa de identificar os aspectos que afetam a satisfação no serviço público, constataram que as rotinas, as especificidades do trabalho e os recursos humanos são fortemente influenciados pelo contexto de trabalho. Da mesma forma, Markovits et al. (20IO), também constataram que a satisfação e o comprometimento são dependentes do contexto organizacional. Nesse sentido, para que o trabalho seja exercido de forma satisfatória e traga resultados tanto organizacionais quanto pessoais, se faz necessário um ambiente propício a isso.

\section{Considerações finais}

A pesquisa teve como objetivo analisar as condições de trabalho dos servidores de uma universidade pública de Sergipe, considerando aspectos motivacionais, de comprometimento e de sofrimento. Para tanto foi feita uma pesquisa quantitativa com uso de questionários com os chefes de departamentos e núcleos e com os técnicoadministrativos.

Os resultados demonstraram que o trabalho do servidor público é executado com certo grau de comprometimento, motivação e ao mesmo tempo sofrimento.

Embora os servidores executem suas atividades com certo nível de comprometimento, existem aspectos próprios do serviço público que acabam limitandoo, mas que podem ser gerenciados se identificados pela gestão. A falta de oportunidade de crescimento e de compensações se mostraram aspectos importantes ao comprometimento.

O ingresso no serviço público muitas vezes significa exercer o mesmo cargo, o 
que a longo prazo pode gerar frustração em virtude das necessidades de crescimento pessoal, auto-satisfação e realização do próprio potencial. Assim, embora as atividades se mostrem satisfatórias inicialmente, com o passar do tempo os servidores desejam um algo a mais que não pode ser obtido dentro do cargo exercido. Nesse sentido, muitos servidores, por não terem essas necessidades atendidas, manifestaram o desejo de se aposentar logo e de terem uma oportunidade de trabalho melhor, que possibilite a realização de suas necessidades.

Aliado a isso, as gratificações oferecidas pelo ingresso em cargos de maior responsabilidade muitas vezes não são condizentes com as atribuições do cargo, gerando insatisfação e pouco interesse no ingresso desses cargos por despertarem no servidor o sentimento de desvalorização da atividade que lhe é repassada. Além disso, como defende a "teoria das necessidades socialmente adquiridas", nem todas as pessoas têm orientação para o poder, de modo que podem preferir executar bem suas tarefas e serem reconhecidas de outras formas, a serem colocadas em cargos de chefia, uma vez que teriam agora que ser motivadoras e se preocupar mais com o desempenho coletivo que com o individual.

Nesse sentido, pode-se compreender o comprometimento como um resultado da motivação, de modo que o servidor só pode desempenhar bem suas atividades se sentir que existe algo que o impulsiona rumo a esse objetivo.

Um aspecto encontrado na pesquisa que afeta a motivação dos servidores públicos é o nível de formação dos mesmos. Como a maior parte dos servidores possui formação além do cargo, é natural que julguem que os salários pagos são inferiores ao esperado. Esse é um dos quadros mais críticos dentre os pontos analisados, pois como falar em motivação e comprometimento com servidores que, podendo ocupar cargos de direção e até mesmo outra função dentro da universidade, continuam como técnicoadministrativos?

Em relação ao sofrimento, foi identificado que os técnico-administrativos enfrentaram diversas experiências aversivas e que os chefes dos departamentos desconhecem estas situações. Os resultados se mostram preocupantes por dois motivos, o primeiro ao demonstrar que os chefes não conhecem o real sentimento dos funcionários quanto ao ambiente de trabalho, e o segundo ao mostrar o ambiente de 
trabalho como um fator de desmotivação. Embora haja empenho por parte da gestão e dos chefes em tornarem satisfatórios o trabalho e os serviços oferecidos, como preconizam as teorias européias, o sonho de um trabalho motivador e prazeroso é bastante difícil de ser realizado, pois sempre haverá questões humanas envolvidas, pessoas com pensamentos diferentes, pouco ou muito interessadas no bem estar do outro, pouco ou muito capacitadas para a atividade que exercem, surgindo aí uma discrepância entre a necessidade da tarefa e o que os servidores têm a oferecer.

Tais resultados sugerem que no setor público a gestão de pessoas deve ter mais foco nas pessoas do que nas tarefas. Para se alcançar um resultado satisfatório as pessoas devem se sentir reconhecidas e ter mais chances de desenvolvimento profissional, uma vez que se preparam para isso. As pessoas em geral sentem-se motivadas à medida que buscam atender as suas necessidades, desde as fisiológicas até as de auto-estima e de realização, mas à medida que cada uma delas é atendida, já não mais se sentem motivadas. Por esse motivo, um plano de carreira é indispensável para o bom aproveitamento dos recursos humanos que a universidade possui.

Percebe-se ao longo da pesquisa que os servidores não são displicentes no que se refere a preparar-se para exercer novas atividades e os gestores de RH precisam aproveitar esse potencial de seus recursos humanos. Em muitas instituições observa-se que o problema é o pessoal que não se move para capacitar-se. Na universidade aqui pesquisada se tem uma situação inversa, preparo de sobra e reconhecimento de menos. Funcionários com pós-graduações, e até cursos de mestrado poderiam ser aproveitados em palestras acadêmicas, em debates sobre a expansão universitária e inseridos em muitos outros projetos desenvolvidos pela gestão de RH, projetos esses que oferecessem recompensas motivadoras e que ajudassem a promover e desenvolver essas pessoas, pessoal e profissionalmente. Alvo esse tão desejado.

\section{Referências}

AMBROSE, M. L; KULIK, C. T. Old Friends, New Faces: Motivation Research in the I99o's. Yearly Review of Management of the Journal of Management, vol. 25, pp. 23I-292, I999.

ARCHER, E. R. O mito da motivação. In: BERGAMINI, C. W.; CODA, R. Psicodinâmica da vida organizacional: motivação e liderança. 2. ed. São Paulo: Atlas, I997.

BERGAMINI, C. W. Motivação nas organizações. 4. ed. São Paulo: Atlas, 1997. 
BERGUE, S. T. Gestão de pessoas em organizações públicas. 3. ed. Caxias do Sul, RS: Educs, 2010.

BORGES, R. Are public officials really less satisfied than private sector workers? A comparative study in Brazil. Revista de Administração Pública, vol. 47, n. 6, pp. 477-496, nov./dez., 20I3.

BOWDITCH, J.; BUONO, A. Elementos de comportamento organizacional. São Paulo: Pioneira, I992.

BOXALL, P. F. The significance of human resource management: a reconsideration of the evidence. The International Journal of Human Resource Mangemente, vol. 4, n. 3, pp. 645-663, I993.

BUTLER, J. E.; FERRIS, G. R.; NAPIER, N. Strategy and Human Resources Management. Cincinnati: South-Western Publishing, I99I.

CAUDRON, S. O que motiva os funcionários. HSM Management, São Paulo, n.I, p. 82-86, mar./abr., I997.

CAVALCANTI, V. L.; CARPILOVSKY, M.; LUND, M.; LAGO, A. Liderança e motivação. Rio de Janeiro: Editora FGV, 2007.

DAVIS, K.; NEWSTROM, J. Comportamento humano no trabalho. São Paulo: Pioneira, I992.

DEJOURS, C. A loucura do trabalho: estudo de psicopatologia do trabalho. 5 ed. São Paulo: Cortez Oboré, I992.

DI PIETRO, M. S. Z. Parcerias na Administração Pública. 3 ed. São Paulo: Atlas, ı999.

DUBRIN, A. Princípios de administração. 4. ed. Rio de Janeiro: Livros Técnicos e Científicos, 2OOI.

FERREIRA, A.; FUERTH, L. R.; ESTEVES, R. C. P. M. Fatores de motivação no trabalho: o que pensam os líderes. XXX EnANPAD - Encontro Nacional de Programas de Pós-Graduação em Administração. Salvador, 2006. Anpad, 2006.

FLAUZINO, D.; BORGES-ANDRADE, J. Comprometimento de servidores públicos e alcance de missões organizacionais. Revista de Administração Pública, vol. 42, n. 2, pp. 253-73, mar./abr., 2008.

GIL, A. C. Gestão de pessoas: enfoque nos papéis profissionais. São Paulo: Atlas, 2010.

HERZBERG, F. Mais uma vez: como motivar seus funcionários. In: Vromm, Victor H. (Org.). Gestão de pessoas, não de pessoal. Rio de Janeiro: Campus, I997.

IGALENS, J. Gestão dos recursos humanos. In: CARRÉ, P; CASPAR, P. Tratado das ciências e das técnicas da formação. Lisboa: Instituto Piaget, I999.

KAISER, L. C. Job satisfaction and public service motivation. IZA, Discussion Paper, n. 7935, 20I4.

LADEIRA, W. J.; SONZA, I. B.; BERTE, R. S. Antecedentes da satisfação no setor público: um estudo de caso na prefeitura de Santa Maria (RS). Revista de Administração Pública, vol. 46 , n. I, pp. 7I-9I, jan./fev., 2 OI2.

LANER, A. S.; BENJAMIN, J. C. J. Indivíduo, organizações e sociedade. Ijuí: Ed, Unijuí, 2008.

LEGGE, K. Human resource management: rhetorics and realities. London: Macmillan Business, I995.

MABEY, G.; SALAMAN, G.; STOREY, J. Strategic human resource management: a reader. London: Sage/Open University Business School, I998. 
MALIK, M. E.; NAWAB, S.; NAEEM, B.; DANISH, R. Q. Job satisfaction and organizational commitment of University Teachers in public sector of Pakistan. International Journal of Business and Management, vol. 5 , n. 6 , june, 2010 .

MARKOVITS, Y.; DAVIS, A. J.; FAY, D.; VAN, R. The link between job satisfaction and organizational commitment: differences between public and private sector employees. International Public Management Journal, vol. I3, n. 2, 2010.

McCLELLAND, D.; DURNHAM, D. O poder é o grande motivador. In: VROOM, V. H. (Org.) Gestão de pessoas, não de pessoal. Rio de Janeiro: Campus, I997.

MORGAN, G. Imagens da organização. São Paulo: Atlas, I996.

MOTTA, F. C. P.; FREITAS, M. E. Vida psíquica e organização. Rio de Janeiro: Editora FGV, 2000.

PIMENTA, S. M. Recursos humanos: uma dimensão estratégica. Belo Horizonte: UFMG, I999.

QUEIROZ, S. H. Motivação dos quadros operacionais para a qualidade sob o enfoque da liderança situacional. Dissertação (Mestrado em Engenharia) - Centro Tecnológico Florianópolis: UFSC, I996.

QUINN, J. B. Intelligent enterprise. New York: The Free Press, I992.

ROBBINS, S. P. Administração: mudanças e perspectivas. São Paulo: Saraiva, 2002.

SALANOVA, M.; HONTAGAS, P.; PIERÓ, J. M. Motivation laboral. In J. M. Peiró; F. Prieto (Eds.), Tratado de Psicologia del trabajo (Vol. 2). Madrid: Síntesis, I996.

SAMPAIO, J. O Maslow desconhecido: uma revisão de seus principais trabalhos sobre motivação. In: XXVIII ENCONTRO NACIONAL DE PROGRAMAS DE PÓS-GRADUAÇÂO EM

ADMINISTRAÇÂO. Curitiba, 2004. Anais... Anpad, 2004. I CD-ROM.

SCHULER, R. S.; HUBER, V. L. Personnel and Human Resource Management, 5 ed. St Paul

Minnesota: West Publishing Company, 1993.

SCHULER, D. New community networks: wired for change. New York: ACM Press, I996.

STEYAERT, G.; JANSSENS, M. Human and inhuman resoucer managemant: saving the subejct oj HRM. The Interdisciokinary Journal of Organization, Theory and Society, vol. 6, n. 2, pp. I8I-I98, I999.

STOREY, J. Human resource management: a critical text. London: Routledge, I995.

TOWNLEY, B. Reframing human resource management. London: Sage, I994.

VERGARA, S. C. Gestão de pessoas. 2. ed. São Paulo: Atlas, 2000.

VERGARA, S. C. Gestão de pessoas. 3. ed. São Paulo: Atlas, 2003.

WEIBEL, A.; ROST, K.; OSTERLOH, M. Pay for performance in the public sector: benefits and (hidden) costs. Journal of Public Administration Research and Theory Advance Access, vol. 27, may, 2009.

ZANELLI, J. C.; BASTOS, A. V. B. Inserção profissional do psicólogo em organizações e no trabalho. In: ZANELLI, J. C.; BORGES-ANDRADE, J. E.; BASTOS, A. V. B. Psicologia, organizações e trabalho no Brasil. Porto Alegre: Artes Médicas, 2004. 